January 2019

\title{
Advancing Student Interview Skills: Incorporating Virtual Interview Technology into the Basic Communication Course
}

Kasey Hudak

Pennsy/vania State University, kch17@psu.edu

Alexandria Kile

Pennsylvania State University, apk3@psu.edu

Eileen Grodziak

Pennsylvania State University, emg15@psu.edu

Elizabeth Keptner

Pennsylvania State University, eab36@psu.edu

Follow this and additional works at: https://digitalcommons.georgiasouthern.edu/ij-sotl

\section{Recommended Citation}

Hudak, Kasey; Kile, Alexandria; Grodziak, Eileen; and Keptner, Elizabeth (2019) "Advancing Student Interview Skills: Incorporating Virtual Interview Technology into the Basic Communication Course," International Journal for the Scholarship of Teaching and Learning: Vol. 13: No. 1, Article 3.

Available at: https://doi.org/10.20429/ijsotl.2019.130103 


\title{
Advancing Student Interview Skills: Incorporating Virtual Interview Technology into the Basic Communication Course
}

\begin{abstract}
This study examined the differences between student's self-reported communication interview skills before and after they received interview instructions and experienced virtual simulation interviews in a basic communication course. Incorporating interview instruction and utilizing mock interviewing software, InterviewStream, into several basic communication courses, this study found a significant difference between students' pre-instruction and post-instruction interview self-assessment scores. A Student Assessment of Learning Gains (SALG) revealed that students reported more confidence in their interviewing skills, were more likely to seek help from career services, and pay more attention to nonverbal communication during the interview (dress, posture, and eye contact) after participating in virtual mock interviews.
\end{abstract}

\section{Keywords}

communication skills, virtual interview, mock interview, basic communication course

\section{Creative Commons License}

cc) (i) $€$

This work is licensed under a Creative Commons Attribution-Noncommercial-No Derivative Works 4.0 License. 
IJ-SoTL, Vol. 13 [2019], N0. 1, Art. 3

\title{
Advancing Student Interview Skills: Incorporating Virtual Interview Technology into the Basic Communication Course
}

\author{
Kasey Hudak, Alexandria Kile, Eileen Grodziak, and Elizabeth Keptner \\ Pennsylvania State University
}

Received 24 April 2018;Accepted 24 May 2018

\begin{abstract}
This study examined the differences between student's self-reported communication interview skills before and after they received interview instructions and experienced virtual simulation interviews in a basic communication course. Incorporating interview instruction and utilizing mock interviewing software, InterviewStream, into several basic communication courses, this study found a significant difference between students' pre-instruction and post-instruction interview self-assessment scores. A Student Assessment of Learning Gains (SALG) revealed that students reported more confidence in their interviewing skills, were more likely to seek help from career services, and pay more attention to non-verbal communication during the interview (dress, posture, and eye contact) after participating in virtual mock interviews.
\end{abstract}

Technical expertise was once all that was needed to secure and keep a job. Today's fluctuating marketplace and steady-stream of technological advances, however, compel companies to place greater importance on communication skills-personal attributes and attitudes, emotional intelligence quotient (EQ), ability to work effectively in teams, and professional communication (National Association of Colleges and Employers, 2016; Finch, Nadeau, \& O'Reilly, 20I2). While interviewers and employers highlight the need for communication skills in potential hires and interns (Helyer, \& Lee, 20I4; Doria, Rozanski, \& Cohen, 2003), some studies suggest that these skills are seemingly lacking in college graduates (Finch, Hamilton, Baldwin, \& Zehner, 20l3; Fischer, 2013; Robles, 20I2).

Compounding this concern are the increasingly mediated experiences of interviews. Employers recurrently use mediated forms of communication-telephone calls, emails, and videoconferencing - to conduct interviews (Blacksmith, Willford, \& Behrend, 2016; Sears, Zhang, Wiesner, Hackett, \& Yuan, 2013; Silvester \& Anderson, 2003). "In the near future, asynchronous interviewing-e.g., where a candidate uploads a video-recorded response to a question presented through a website-may become the norm" (Kyllonen, 20I3, p. 22). Interviewing inherently contains some amount of stress, but adding a technological component could "throw-off" some applicants (Straus, Miles, \& Levesque, 200I). Not to mention that nonverbal communication saliency diminishes with mediated interviews (Dunbar, Jensen, Burgoon, Kelley, Harrison, Adame, \& Bernard, 2015; Chapman \& Rowe, 200I, 2002; Angiolillo, Blanchard, Israelski, \& Mané, 1997). Toldi (20II) notes, "Job applicants need to be educated on the video-interviewing process to help ease their hesitation with the change to the talent-acquisition process" (p. 26).

Tantamount to the issue of interviewing instruction is the discussion of its proper home. Most colleges have career service departments that offer interviewing aid, but students nationwide claim that online career service interviewing practices and workshops are not effective (NACE, 2016). Alternatively, interviewing skills are core components in marketing and business courses (Finch, Nadeau, \& O’Reilly, 20I2; Myers \& Tucker, 2005; Taylor, 2003); and although these courses may count as electives, students outside of those majors may not take these courses. With the rise of internships across all disciplines (NACE, 20I7), and a call to increase interviewing skills within the STEM fields (Kurtz, Silverman, \& Draper, 2016; Kinzel, Veltsos, Bates, Cohen, Sealy, \& Nykanen, 20I5), a basic communication course that is characteristically an elective for all majors arguably reaches more students and gives them a foundation in a necessary skill (Valenzano, Wallace, \& Morreale, 20 I4; Morreale, Hugenberg \& Worley, 2006).

The purpose of this study is to examine the differences between student's self-reported communication skills before and after they experienced interviewing instructions and virtual simulation interviews in a basic communication course. A case study utilizing a mixed-methodology approach was conducted to explore students' prior interview experiences, interactions with campus career services, and communication skills self-assessments. Five basic communication courses that employed interviewing strategy coursework and virtual simulation interviewing software, InterviewStream, were examined to assess differences between students' interviewing skills before and after interviewing instruction and mock interviews.

\section{LITERATURE REVIEW}

When it comes to interviewing, employers seek potential hires that demonstrate superior nonverbal behaviors (e.g., eye-contact, smiling, body language, hand movement, and physical appearance) and verbal communication skills, while exhibiting job-relevant knowledge that lends to their credibility (Helyer, \& Lee, 2014; Sears et al., 20I3). Stewart, Wall and Marciniec (2016) surveyed over 2I 4 college students at a four-year university about their communication skills confidence levels: $84 \%$ claimed confidence in written communication, $83 \%$ in teamwork skills, and a little over $72 \%$ felt they had verbal communication skills (p. 276); but the authors also discovered "a widening gap between employer expectations and college graduate abilities" (2016, p. 276). The Chronicle of Higher Education identified that nearly a third of the American Public Media's Marketplace employers gave four-year degree colleges "just fair to poor marks for producing successful employees. And they dinged bachelor's-degree holders for lacking basic workplace proficiencies, like adaptability, communication skills, and the ability to solve complex problems" (Fischer, 20I3, para. I).

Regardless of interview format (face-to-face versus videoconference) interviewees are assessed on their ability to fully 
communicate the aforementioned communication aptitudes. Measuring the disparities between face-to-face and videoconferencing employment interviews, Sears et al. (2013) indicated that a lack of videoconferencing knowledge (i.e., tips for effectiveness, procedures, and performance variables) led to negative perceptions of mediated communication skills. On one hand, these studies suggest that today's college students become more successful in the employment arena when they possess practical interviewing strategies presented by superior communication skills. On the other hand, these same studies found a dearth of these skills in college graduates.

\section{Interviewing Skills and Strategies for the $21^{\text {st }}$ Century Classroom}

One area of communication skill assessment, the interview, affords the ability to gauge an individual's competency, attractiveness (e.g. friendliness, likability and affable qualities), and trustworthiness (Chapman, Uggerslev, Carroll, Piasentin, \& Jones, 2005). Interviewers often use open-ended questions that "elicit evidence that the applicant possesses those skills," which can simultaneously reveal an interviewee's "drive, enthusiasm, or customer orientation" toward the company and its clients (Kyllonen, 20I3, p. 2I). Many colleges offer interviewing strategies through their career services department; but despite a trend in career services to include networking and career development support (Dey \& Cruzvergara, 2014), NACE's 2016 Internship Report found that only $17 \%$ of students claim their services to be helpful, with students ranking career services' online practice interviews and online career development workshops as some of the least effective services.

In terms of classroom instruction, interviewing skills are primarily found in business, marketing, and management courses. Students outside of those majors are not often required to take such courses. Whereas a basic communication course is a "communication course either required or recommended for a significant number of undergraduates; that course which the department has, or would recommend as a requirement for all or most undergraduates" (Morreale, Hanna, Berko, \& Gibson, 1999 , p. 3). According to Valenzano et al. (20I4), the basic communication course might be the only time that students outside of that major might get instruction in communication skills. Britt, Brockman, Casson and Johnson, (2016) further observe that technical skills, people skills, and interviewing skills are the greatest takeaways students can acquire from basic communication courses for use in the marketplace.

Traditional basic communication curriculum primarily focuses on public speaking strategies, like effective speech techniques, speech anxiety exercises, and persuasion, i.e., rhetoric (Hancock, Stone, Brundage, \& Zeigler, 20I0; Johnson \& Szczupakiewicz, 1987). Less than twenty years ago, basic course topics shifted to include interpersonal dimensions (race, ethnicity, and diversity), as well as technology and assessment concerns (Goodnight \& Wallace, 2005; Morreale et al., 1999). Surveying over 188 basic course instructors, Morreale, Myers, Backlund, and Simonds (2016) asked their respondents to list the topics from their textbooks that they chose not to teach. "The most frequently listed topics (i.e., listed by 7-9 respondents) included small group communication, interviewing, and special occasion speaking" ( $p$. 349). A brief review of the current popular basic communication course textbooks: Communication: Principles for a Lifetime, Public Speaking Handbook; The Art of Public Speaking; and Understanding Human Communication (also identified by the Morreale et al. 2016 survey), uncovers that only a chapter, if any, are dedicated to technological instruction. Moreover, these chapters concentrate on "using presentation media" with no indications of video or mock interview instructions.

The argument can be made that a basic communication course is already too jammed-pack of requirements to add an additional objective. Nevertheless, extemporaneous speaking-a semi-prepared speech with a delivery that sounds spontaneous and unrehearsed-is a common skill taught in public speaking, the preferred content of the basic communication course (Morreale et al., 2016). The value of extemporaneous speaking relates to interviewing; students may not know the exact questions a potential employer will ask, but they can plan in advance responses to popular interviewing topics (educational and professional experiences, knowledge and expertise in the job at hand, and approaches to working with others). During their study of employers' views of basic course instruction, Hooker and Simonds (20I4) found that extemporaneous speaking was "one of the most important skills" mentioned by professionals on the panel (p. 108). Panelists further stated that "employees need the ability to think before they speak and respond to others on the fly based on knowledge they have previously obtained and mentally organized" (Hooker \& Simonds, 2014, p. 108). Participating in a mock interview not only demonstrates extemporaneous speaking skills, but also gives students the opportunity to engage, prepare, and practice communication skills obtained in the classroom outside of the educational environment.

\section{Mock and Simulated Interview Training}

Mock interviews develop and sharpen understandings of the interview process, the student's chosen industry, and their strengths and weaknesses as a skilled worker (Rowell \& Mihuta, 20 16). Hansen, Oliphant, Oliphant and Hansen, (2009) cite mock interviews as a crucial curriculum element to boost student confident and performance. They help students enter conversations without the expectation that they will receive a job offer or an internship. Stocco, Thompson, Hart, and Soriano (2017) incorporated behavioral skills training (BST) - instruct, model, practice, and provide feedback - in their individualized mock interviews. These personalized training lessons included reflective sessions for students to assess training received and post-interview evaluation. Taylor (2003) states the value of this tiered approach:"For many students, these insights are quite important in minimizing their anxiety and increasing their confidence about job interviews (p. 100)." An added benefit to interview training is that students begin to think of themselves as professionals, which encourages self-branding aptitudes.

Research on the role of video technology in interview preparation reveals that individuals seem to perform better both verbally and nonverbally in interview settings when they practice, observe themselves through video replay, and receive focused feedback from others (Barnes, 20l4). Stemming from two studies of over 700 college students, LeFebvre et al. (2016), concluded, "video self-evaluation positively influenced student ability for predictive goal-setting, improved accuracy for assessing speech quality, and diminished overestimation from the informative to persuasive speech" (p. I16). Using a mixed-reality setting (a vir- 
tual classroom with a live-person participating via Skype), Walker et al. (2016) discerned a significant increase of interviewing social skills in individuals with intellectual disabilities' when interview coaching was partnered with virtual learning environments. The value of a mixed-reality approach, according to the authors, affords a "seamless and efficient way to offer instruction with various people," and "provides teachers the ability to 'take' their students to new environments without ever leaving the classroom lab" (Walker et al., 2016, p. 83). One interesting observation Walker et al. (2016) note is that a mixed-reality setting permits "individuals to practice these skills in a setting that is realistic but does not result in harm to the participant or the 'practice partner' since they (the partner) are not real" (p. 84).

In two separate studies, Smith et al. (2015) found that after six months, young adults with high-functioning autism spectrum disorder (ASD) and schizophrenia had greater odds of attaining a competitive job position than those not receiving virtual reality job interview training. The researchers used SIMersion LLC software, Virtual Reality Job Interview Training (VR-JIT), to produce customizable interview questions, which identified and adapted interviewee-specific accommodations. Such adaptations facilitated rapport and dialogue during the interview, thereby enhancing an interviewee's overall poised appearance. That same year, Smith et al. (20I5) used VR-JIT to help veterans with posttraumatic stress disorder. They found that veterans participating in at least I0 hours of VR-JIT reported that the software was, "easy-to-use, enjoyable, helpful, instilled them with confidence, and made them feel well-prepared for future interviews" (pg. 278). Moreover, the veterans claimed that having more confidence in their interviewing skills also improved their possibilities for job outlooks.

Important to mention are the negative findings of using technology for job interviewing. Telephone interviews completely eradicate non-verbal communication, like eye contact and smiling, therefore impeding impression management tactics (Blacksmith et al., 20I6). Technology-mediated interviews can "hinder socio-emotional interactions, which likely lowers perceptions of applicants' social skills" (Blacksmith et al., 20I6, p. I3). Virtual interviewing can be in real time like Skype and Adobe Connect, but can also be performed as asynchronous recorded interviews. Job applicants can record their responses and then submit via online platform, completely replacing any form of interpersonal interaction (Brenner, Ortner \& Fay, 20I6). Toldi (20II) and Guchait, Ruetzler, Taylor and Toldi (2016) further found that when companies did not provide test-runs or training on the technology prior to the interview, candidates felt the process was unfair.This literature led to several questions for the present study:

- Research Question I: How do students' prior interview experiences impact students' self-assessments of interviewing skills?

- Research Question 2: How do students' prior interactions with the campus career services office and programs impact students' self-assessments of interviewing skills?

- Research Question 3: What are the differences between students' self-assessments of interviewing skills completed before interview strategy instruction and the self-assessments of interviewing skills completed after interview strategy instruction?

\section{METHODOLOGY Research Design}

During the semester, approximately two hours of class sessions were devoted to instruction in employment interview strategies. Instructional activities (e.g., short lectures, class discussions, tellme-about-yourself student worksheet, employment interview scenario simulation, and interviewing a professional) addressed the following topics and introduced students to corresponding strategies for professional employment interviews: (I) The purpose behind typical and difficult interview questions; (2) the process for crafting and articulating direct, concise answers to typical and hard interview questions; (3) professional communication style required for employment interviews-English grammar free of slang and generational jargon; (4) non-verbal communication elements essential in an employment interview in the United States; (5) professional dress and appearance for an interview setting; and (6) room backdrop staging for a professional virtual interview.

Employment interview scenario simulations were completed prior to and concluding interview strategies instruction using InterviewStream, an online interview simulation product available to individuals, agencies, businesses, and institutions for job interview preparation and hiring. InterviewStream offers two products: InterviewStream Hire for businesses, and InterviewStream Prep for education. Using a restrictive access feature, InterviewStream Prep allows instructors to create a customized virtual mock interview. From a question bank of over 7,000 pre-recorded typical job interview questions, instructors can select the questions appropriate to the context. Students can then participate in a simulated mock interview web interface, receiving a question prompt to which they respond. Simultaneously, the computer device's camera records and publishes the recording for immediate review. Students may then review their recorded response, self-assess their performance, and share their recording with their instructors for evaluation. Rollins College and The University of Richmond used InterviewStream to simulate a Skype interview and noted the value of using such software:

InterviewStream a) replicates the experience of being interviewed by someone who you do not know and thus enables both respondents to be more open and honest with their performance and feedback; and b) models and thus prepares students for the kind of virtual interviews they likely will encounter during their job or internship search (i.e. phone, Skype, YouTube interviews). (Matthew, Meehan \& Chancy, 2014, p. 76)

With this in mind, the following study utilized InterviewStream as a platform for mediated interview practice.

A five-question interview question set and a custom self-assessment was used for student learning feedback and evaluation. Students used a corresponding course section assignment code to access and open the assignment. Students then viewed a video recording in which a pre-recorded, simulated individual welcomed the student interviewee and posed each interview question. Students answered five common interview questions that probed open-ended responses: introduction of self, identification of strengths, identification of weaknesses, explanations of organizational skills, and explanations of problem-solving skills. A countdown (3-2-I) prompted the student to begin responding to the question, while InterviewStream Prep simultaneously video 
recorded the student's response.When the interview concluded, InterviewStream Prep immediately encoded the video recording, making it viewable within minutes for assessment.

Items to examine student interaction with career services and interview experiences were crafted and added to a post-instruction Student Assessment of Learning Gains (SALG). The SALG is an existing verified instrument used to evaluate a student's self-perception of instructional activities on employment interview strategies. The SALG website (http://www.salgsite. org/) provides a web tool for constructing the validated instrument (see Figure I).

\section{Respondents and Recruitment}

Study respondents were recruited from undergraduate students enrolled in all five course sections of the introductory speech communication course, CASI00 Effective Speech, during the Spring 2016 semester at The Pennsylvania State University (Penn State) Lehigh Valley campus, Center Valley, PA. The Lehigh Valley campus enrolled approximately 820 total students during study semester, of which 103 students enrolled in CASI00.The course is a general education requirement for all Penn State baccalaureate degrees that students generally complete during their first two years at the University. As a result, the course primarily enrolls freshman and sophomore students from a variety of academic majors. Approval for the educational study was secured from the University's institutional review board (study \#3868).

During the CASI00 class session, co-investigators verbally invited registered students to voluntarily participate in the research study (using IRB-approved invitation script). Paper copies of the informed consent were distributed to a total of 103 students across the five sections. Seventy-five percent of invited students positively signed and returned the informed consent to participate in the study ( $\mathrm{N}=77 ; 75 \%$ response rate). The mean age of study respondents was 19.96 years, with a standard deviation of 4.36 years. Categorization of student age as traditional (ages 18-23) and adult (ages 24-50) revealed 94\% were traditional age students $(\mathrm{N}=72)$ and $6 \%$ were adult students $(\mathrm{N}=5)$. Further classification as freshman (one-two semesters), sophomore (three-four) and above sophomore standing reveals $78 \%$ were freshman ( $N=59)$; $16 \%$ were sophomores $(N=12)$; and, $6 \%$ were above sophomore standing $(\mathrm{N}=5)$. The semester classification scale assumes full-time student status and does not factor the probability of inflated semester status for part-time student respondents. The mean semester status was 2.46 semesters completed, with a standard deviation of I.37 $(\mathrm{N}=76)$. Male students $(\mathrm{N}=47)$ accounted for $61 \%$ of the respondents and $49 \%$ were female $(\mathrm{N}=30)$ (see Table I).

\section{Data Instruments}

Two new assessment instruments were created to collect data for this study, the Employment Interview Strategies (EIS) and the employment interview scenario simulation/InterviewStream Self-assessment (ISSA). The EIS contained scaled and open-ended items, querying respondents on their prior experience in employment-related interviews (an approximate total number of interviews, the type of employment, the technologies used during the interview process, and an explanation of the experience during the interview setting), and their prior interactions with the campus career services office (multiple-answer scaled item).

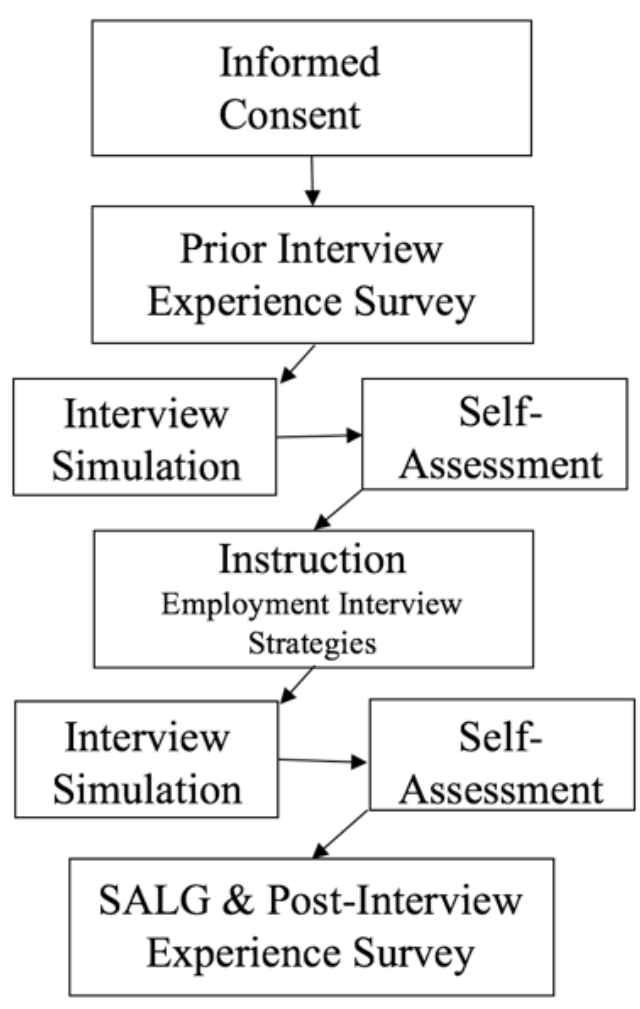

Figure I. Research Design

The ISSA instrument was created using the InterviewStream Prep web application and customized to assess the desired learning outcomes: (I) articulation of a clear, concise response that addresses the question objective and includes a life example; (2) use of professional verbal communication elements; (3) use of professional non-verbal communication elements; (4) physical appearance of the student; and (5) room staging. After completing each interview simulation, study respondents reviewed their verbal and non-verbal communication via the recorded interview video. They responded to 25 items using a 5-point Likert-scale. Less than half of the study respondents completed both self-assessments ( $N=37,48 \%$ response rate).

Item responses from all data instruments were individually entered in Qualtrics survey software. All scaled and multiple response items were analyzed for frequency distribution and descriptive statistics (ordinal and scaled responses). Open-ended items were imported to NVivo qualitative analysis software and coded for themes and frequency. ISSA scores were analyzed using IBM SPSS statistical software to determine significant difference between self-assessment scores before and after interview strategy instruction.

\section{DATA ANALYSIS \& RESULTS}

Prior participation in at least one employment-related interview was reported by $88 \%$ of the study respondents $(\mathrm{N}=68)$. Twelve percent reported no prior employment-related interview experience $(N=9)$. Sixty-seven respondents recorded a specific number of prior interviews in an open text response $(\mathrm{N}=67$, mean 2.82, standard deviation 2.29, $\mathrm{L}=0, \mathrm{H}=10$ ). The ordinal response $(\mathrm{N}=37)$ was further classified as a range of one or two inter- 
Table I. Student Respondent Demographics

\begin{tabular}{|l|l|l|l|l|}
\hline Item & N & \%* & M & SD \\
\hline Age & & & & \\
\hline Total responses to item & 79 & 1.00 & 19.96 & 4.36 \\
\hline Traditional (ages I8-23) & 72 & 0.94 & & \\
\hline Adult (ages 24-50) & 5 & 0.06 & & \\
\hline Semester Status & & & & \\
\hline Total responses to item & 76 & 1.00 & 2.46 & 1.37 \\
\hline Freshman (one-two semesters) & 72 & 0.78 & & \\
\hline Sophomore (three-four semesters) & 59 & 0.16 & & \\
\hline Above sophomore standing (five or more semesters) & 12 & 0.06 & & \\
\hline Gender & & & & \\
\hline Total responses to item & 77 & 1.00 & & \\
\hline Male & 47 & 0.61 & & \\
\hline Female & 30 & 0.49 & & \\
\hline *Percentage of the total number of students who responded to the survey item. & \\
\hline
\end{tabular}

views $(55 \%)$, three or four interviews $(33 \%)$, five to nine interviews $(6 \%)$, or ten interviews $(6 \%)$. No student had participated in a mock interview prior to the effective speech course (see Table 2).

When asked to explain their prior interview experience, students provided open text responses for a $78 \%$ response rate. Themes from response analysis clustered in three areas: overall outcome, performance, and mechanics. The most referenced outcome was a positive nature of the interview (twenty-six references), with descriptors such as, "very good," "went well," and "ok." What went well during their previous interview experiences included comments like, "asked questions," "made eye contact," and "acted confident." A sub-theme of the overall positive outcomes was a sense of ease, with comments about the interview being "relaxed" and "informal." Two references attributed the sense of ease to previously knowing the interviewer. Overall negative outcomes included such descriptions as, "horrible," and "totally bombed." As for what went wrong, students commented: "didn't know how to answer the questions," "took too long to answer," and "was late." When asked what interviewing skills needs improvement, many students replied that they needed "more eye contact."

Comments on interview mechanics clustered in three areas: technology used to conduct interview, types of questions, and interview setting (public and controlled location; individual and group scenario). Thirty-three students indicated participation in faceto-face interviews (12\%). Sixty-eight students responded using technology for their interviews (88\%). Approximately half of the students who reported using technology had interviews conducted via email $(47 \%$, $\mathrm{N}=32$ ); and a lesser percent reported using telephone (37\%; $N=25)$. Only a handful of students reported text-messaging and web conferencing technologies (16\% text, $\mathrm{N}=4$; $16 \%$ web conferencing, $\mathrm{N}=4$ ). Two students identified other technologies used during the interview process: Twitter (student was recruited through Twitter) and company website (student typed responses into a website) (see Table 2). Students were asked questions relating to experience and qualifica- tion, behavioral questions (requiring a work example to illustrate performance or work quality attribute), and philosophical or hypothetical questions.

When asked to select interview type (paid job, student position, internship or volunteer/job shadow) in which they participated DURING the CASI00 course, thirty students reported having participated in forty-one interviews during the course term $(39 \%$ response rate). During the CASI00 course, fifty-six respondents also indicated that they interacted with career services (73\% response rate). Their interactions with career services included: attending the Etiquette Dinner $(\mathrm{N}=15)$; utilized drop-in career counseling $(N=8)$; attended a career or internship fair $(N=8)$; stopped to speak with visiting recruiters at a display in the main academic entrance $(\mathrm{N}=32)$; had career services review their resume $(\mathrm{N}=20)$; scheduled an appointment to meet with a career services specialist $(\mathrm{N}=9)$; attended the annual Dress for Success event $(\mathrm{N}=10)$; had their cover letters reviewed $(\mathrm{N}=10)$; and participated in a mock interview outside of the course $(\mathrm{N}=6)$. The majority of student respondents, $66 \%$, claimed to have a negative response of their interactions with career services $(N=5 I)$, while $34 \%$ responded positively $(\mathrm{N}=26)$. Several students reported "mixed messages" from different advisors within the career services department, resulting in inconsistencies in interview instruction. Students also did not feel "comfortable" during the interaction (as opposed to knowing their course instructor), and some "aloofness" on the part of career services. Over twenty-five more interactions with career services occurred during the course than prior to the CASI00 course (see Table 3).

\begin{tabular}{|c|c|c|c|c|c|c|}
\hline \multirow[t]{2}{*}{ Item } & \multicolumn{4}{|c|}{$\begin{array}{l}\text { Prior Interview } \\
\text { Experience }\end{array}$} & \multicolumn{2}{|c|}{$\begin{array}{l}\text { During } \\
\text { Course }\end{array}$} \\
\hline & $N$ & $\%$ & $M$ & $S D$ & $N$ & $\%$ \\
\hline Total study participants & 77 & & & & & \\
\hline \multicolumn{7}{|l|}{ Participated in prior interview? } \\
\hline Yes & 68 & $88 *$ & & & & \\
\hline No & 9 & $12 *$ & & & & \\
\hline Total number & 77 & & 2.96 & 2.29 & & \\
\hline Students with prior interview: job type & 68 & $88 *$ & & & 30 & $39 *$ \\
\hline Part-time job & 58 & 86 & & & & \\
\hline Full-time job & 14 & 21 & & & & \\
\hline Total paid job interviews & 61 & $79 *$ & & & 73 & 22 \\
\hline Internship & 11 & 16 & & & 40 & 12 \\
\hline Volunteer/Job Shadow & 16 & 24 & & & 23 & 7 \\
\hline Students with prior interview: technology type & 68 & $88 *$ & & & & \\
\hline No technology, face-face & 33 & 49 & & & & \\
\hline Email & 32 & 47 & & & & \\
\hline Telephone & 25 & 37 & & & & \\
\hline Text Messaging & 4 & 16 & & & & \\
\hline Online web conference tool, such as Skype & 4 & 16 & & & & \\
\hline Online technology, other (Twitter, website) & 2 & 8 & & & & \\
\hline \multicolumn{7}{|c|}{$\begin{array}{l}\text { *Response rate of study participants; default is the percentage of total students re- } \\
\text { sponding to the item. } \\
\text { **Percentage of students who responded, "Yes, I have participated in an interview prior } \\
\text { to this class." }\end{array}$} \\
\hline
\end{tabular}




\begin{tabular}{|c|c|c|c|c|c|}
\hline \multirow[t]{2}{*}{ Items } & \multicolumn{2}{|c|}{ Before Course } & \multicolumn{2}{|c|}{ During Course } & \multirow[t]{2}{*}{ Difference } \\
\hline & $\% *$ & $\mathrm{~N}$ & \%* & $\mathrm{N}$ & \\
\hline \multirow[t]{2}{*}{ Total study respondents who responded to the item } & 47 & 36 & 73 & 56 & 20 \\
\hline & $\% * *$ & & $\% * *$ & & \\
\hline Stopped to speak with recruiters in center hall & 31 & 11 & 57 & 32 & 11 \\
\hline Etiquette Dinner & 47 & 17 & 28 & 15 & -2 \\
\hline Dress for Success Program (annual program) & 11 & 7 & 18 & 10 & 3 \\
\hline Drop-in Career Counseling & 36 & 13 & 14 & 8 & -5 \\
\hline Scheduled an appointment for career or internship counseling & 28 & 10 & 13 & 9 & -1 \\
\hline Resume Review & 31 & 11 & 36 & 20 & 9 \\
\hline Cover Letter Review & 6 & 2 & 14 & 10 & 8 \\
\hline Mock Interview & 0 & 0 & 35 & 7 & 7 \\
\hline Attended a career or internship fair & 36 & 13 & 18 & 6 & -7 \\
\hline Total difference in number of interactions & & & & & 25 \\
\hline
\end{tabular}

viewStream scenario before the interview strategies instruction and after the interview strategies instruction (see Table 6). There was a significant difference in the self-assessment scores for the InterviewStream interview scenario before the interview strategies instruction $(M=80.3, S D=15.7)$ and the self-assessment scores $(M=98.1, S D=14.6)$ after the instruction; $t(5 \mathrm{I})=17.36 ; \mathrm{p}<.05$.

\section{DISCUSSION}

Of our sample survey, $78 \%$ of students were first or second-year students, and $88 \%$ of them said that they have already

Seventy-seven students completed the SALG (see Table 4). Respondents reported "moderate" to "good" gains in three of the five skills: ability to manage non-verbal behaviors in a mock interview setting $(M=3.92)$, dress professionally $(M=3.97)$, and stage room environment for a web-based interview $(M=3.92)$. Respondents perceived slightly higher gains ("good" to "great") in two skills relative to employment interview strategies: ability to operate web interview technology $(M=4.03)$ and ability to articulate coherent responses to interview questions $(M=4.04)$. Moreover, they perceived "good" to "great" gains in three attitudes: confidence that they can interview effectively $(M=4.04)$, willingness to seek help from other when preparing for employment interviews $(M=4.12)$, and confidence of understanding employment interview strategies $(M=4.18)$. Overall understanding of interview strategies $(M=4.43)$ and the degree of how respondents' understandings of interview strategies changed as a result of the class $(M=4.36)$ achieved the highest perceived gain. The attitude of willingness to discuss interview strategies with friends or family achieved the lowest perceived gain $(M=3.55)$.

Of the sixty-three students who answered the question of how they will use the interview strategies learned in CASI00, $53 \%$ reported using the interview strategies during an interview that occurred while taking the course $(N=33)$; $17 \%$ referenced planning to use the strategies learned in future interviews $(\mathrm{N}=19)$, and $30 \%$ indicated that they did not use the strategies $(\mathrm{N}=\mid 4)$. Further analysis of the responses clustered around three major themes: actions students took, feelings of confidence, and employment outcomes.

Students were asked to complete a performance assessment immediately following their first (pre-instruction) and second (post-instruction) InterviewStream attempts (see Table 5). Thirty-seven students completed both the pre-instruction interview simulation self-assessment (ISSA) and the post-instruction ISSA ( $N=37,48 \%$ response rate). One ISSA record (pre-instruction and post-instruction per study participant), produced extreme outlier results; therefore, the record was eliminated from the data analysis. Using the Likert-scaled equivalents ( $\mathrm{I}=$ very poor, 2 = poor, 3 = acceptable, 4 = good, 5 = very good), a total score was calculated for each participant's pre-instruction ISSA and post-instruction ISSA. A dependent-samples t-test was conducted to compare the students' total ISSA scores from the Inter- to the course. These findings support our belief that interview skills need to be taught in introductory basic communication college courses, as the number of freshman and sophomores already having job interviews was an unanticipated, but interesting discovery. Additionally, technology was overwhelmingly the primary means through which the interviews were conducted (88\%), and several students who had technology-mediated interviews indicated that this method had a few disadvantages over face-to-face interviews. Students who had technology-mediated interviews felt that their personality did not "show through" this type of communication, or they were not as dynamic and interactive with their interviewer as they perceive themselves to be in face-to-face communication situations. Open-ended responses on what went wrong during the interview frequently mentioned lack of eye-contact, which may be limited or completely omitted via technology (Blacksmith et al., 2016; Barnes, 2014). This supports our stance that virtual interviewing instruction is also needed at the introductory college level to increase students' understanding of, and aptitude with, mediated interviewing techniques.

After participating in the virtual mock interviews, students reported that their feelings of confidence and employment outcomes were positively affected. Comments noted specific confidence-boosting strategies like,"having prepared elevator speech," and "required me to work on my posture and eye-contact." Students also noted that their knowledge, skills, and attitudes relative to employment interview strategies were moderately to greatly enhanced thanks to InterviewStream's mock interview exercises. One student stated:"I've learned so much more about networking and how to properly write resumes, cover letters, etc. that has already helped me find an internship this summer."

Students felt that the first round of InterviewStream (where they went in with no previous training or instruction) was not helpful, and instead felt like confidence diminished seeing how "bad" their first interview went. After the second-round interviews, however, students' self-assessments of the interview simulation ( $M=3.64)$, and discussions on strategies for successful InterviewStream practices $(M=3.75)$ seemed to have the greatest impact on their learning. "What I liked best is the fact that our class learned tips and strategies that can be used in real life experiences such as interviews, networking and resume building." 
Table 4. Student Assessment of Learning Gains (SALG)

Item

As a result of your work in this class, what gains did you make in your understanding of ElS?

How much has your understanding of EIS changed as a result of this class?

Skills: As a result of this class, what Gains did you make in:

Articulate coherent responses to interview questions

Manage non-verbal behaviors in a mock interview setting

Dress professionally.

Stage room environment for a web-based interview

Operate web-based interview technology

Class impact on attitudes: As a result of your work in this class, what gains did you make in:

Enthusiasm about the subject - EIS

Interest in discussing EIS with friend or family

Interest in attending or planning to attend additional programs on employment EIS

Confidence that you understand EIS

Confidence that you can interview effectively

Confidence in operating a web based interview tool

Willingness to seek help from others (teacher, peers, etc.) when preparing for job interviews

Integration of learning: As a result of your work in this class, what gains did you make in:

Connecting key EIS with other knowledge (in other classes or outside of school).

Applying what I learn in classes to other situations

The Class Overall: How much did the following aspects of the class help your learning?

The instructional approach taken in this class for the EIS instruction

How the EIS activities, reading and assignments fit together

The pace of the interview strategy instruction

Class Activities: How much did the following aspects of the EIS Instruction help your learning?

Attending the interview strategies lecture portion of the class

Participating in interview strategy discussion during class

Listening to others during interview strategy discussions in class

Participating in group activities on interview strategies during class

Graded Activities: How much did each of the following aspects of the class help your learning?

Tell me about yourself worksheet

The first interview using InterviewStream

The self-assessment of your interview recording

The second interview using InterviewStream

Class Resources: How much did each of the following aspects of the class help your learning? Interview strategy materials provided during class

The online instructions on how to use InterviewStream

$* I=$ No gains; 2 = A little gain; 3 = Moderate gain; $4=$ Good gain; $5=$ Great gain.

**I $=$ Not at all; 2 = A little; $3=$ Somewhat; $4=$ A lot; $5=$ A great deal.

EIS - Employment Interview Strategies; abbreviated for this table.

This corresponds with our belief that learning outcomes and interviewing skills can be enriched with mock interviews that offer "safer" practicing environments: students can refine their communication and interview skills, and still save-face due to the lack of public or "real" interactions.

\section{LIMITATIONS AND FUTURE RESEARCH}

This study took place over one semester, across five different courses and with three different instructors. This results in limitations relevant to course instruction (teaching skills and approaches) differing slightly among the three instructions. Furthermore, we did not inquire as to what other interviewing strategies or techniques students may have been learning in their other classes, nor did we include a control group of students who did not engage in the interview instructions or mock interviews. Germane to this limitation is the issue of using one product, InterviewStream, to conduct mock interviews. We do not claim superiority of this product over other virtual simulation software, or the freely available use of web tools like Skype and Adobe Connect, to conduct mock interviews. Future research could compare student outcomes amongst a variety of instructional tools to fully investigate the utility of instructional methods; as well as explore extemporaneous speaking skills that might be taught in other courses (business, leadership, organizational communication courses, etc.). Having data from career services of what students seek when they ask for help, including any corresponding findings from their data on student internships and alumni job acquisitions, will help progress classroom instruction approaches and topics as they relate to interviewing skills.

The respondents were overwhelmingly first or second-year students, which supports the claim for earlier instruction in a student's college career, but ultimately constrains generalizability of the campus population. The low response rate for the second, post-test could have resulted in overall lower scores across the data. Exact data on the reason for the low response rate was not recorded. However, it is speculated that this was in part due to the time of year (end of semester) when it was administered, where students may have missed class that day to study for other finals. The instructors also did not follow-up with the students who did not take the second post-test.

Lastly, this study chose not to disclose instructors' scores in this report. The goal was to see I) if college students could be objective towards their own communication skill-levels, and 2) how self-assessments of those skills changed as result of instruction.A future study would include assessments by investigators, i.e., expert rating, whose scores would be averaged into the student's self-rating. This would enhance an inter-rater reliability score and help determine if the student self-ratings are valid as compared to the instructor's scores. Investigators will also in- 
Table 5. Interview Simulation Self-Assessment (ISSA)

\section{Items}

Question I:Tell me about yourself.

a) Response is an organized synopsis of self.

b) Includes life experience(s) to provide examples of traits, strengths mentioned.

Question 2:What is your greatest strength?

a) Clearly identifies a personal strength relative to employment goals.

b) Includes a related life experience example.

Question 3: Give an example of a weakness and how you have worked to correct it.

a) Explains a personal weakness in a positive way.

b) Explains process used/using to improve weakness.

c) Includes a related life experience example.

Question 4: Give me an example that demonstrates your ability to organize when you have multiple tasks to accomplish.

a) Clearly explains planning/prioritizing scenario.

b) Identifies a process employed in planning/execution.

c) Provides a life experience that demonstrates planning and prioritization.

Question 5: Tell me about a time when you have had to use good decision making and problem-solving skills in order to accomplish something.

a) Includes meaningful problem-solution scenario.

b) Identifies resources used to solve a problem.

c) Includes a life experience example that demonstrates a problem-solution scenario.

Overall Performance:Verbal Communication

a) Responds to the question/Sticks to the subject.

b) Uses professional English grammar, free of slang.

c) Demonstrates fluent speech, free of filler words (um, uh, etc.).

Overall Performance: Non-Verbal Communication

a) Uses direct eye contact (in the recording, the interviewee is looking directly at the interviewer)

b) Demonstrates upright posture.

c) Smiles.

d) Avoids distracting movements (such as finger tapping, gum chewing, etc.).

e) Appears self-confident.

Physical Appearance

a) Interviewee is groomed (combed hair, shaved/clipped facial hair, clean hands).

b) Interviewee wears business attire (shirt/tie, blouse/shell, sweater/jacket in dark neutral colors).

Setting

a) Visible background behind interviewee is neutral, with nothing to take focus from interviewee)

b) Interview simulation was recorded with camera at interviewee's eye level.

\begin{tabular}{|c|c|c|c|c|c|c|c|c|c|c|}
\hline \multirow[b]{2}{*}{ Item } & \multirow[b]{2}{*}{$N$} & \multirow[b]{2}{*}{ M } & \multirow[b]{2}{*}{ SD } & \multirow[b]{2}{*}{ Correlation } & \multirow[b]{2}{*}{ Sig. } & \multicolumn{5}{|c|}{ Dependent Samples t-Test } \\
\hline & & & & & & $\begin{array}{l}\text { Paired Differences } \\
95 \% \text { confidence } \\
\text { Interval of the } \\
\text { Difference Lower }\end{array}$ & $\begin{array}{l}\text { Paired Differences } \\
95 \% \text { confidence } \\
\text { Interval of the } \\
\text { Difference Upper }\end{array}$ & $\mathrm{t}$ & df & $\begin{array}{l}\text { Sig. } \\
\text { (2-tailed) }\end{array}$ \\
\hline ISSE I & 36 & 80.33 & 15.92 & & & & & & & \\
\hline ISSE 2 & 36 & 98.08 & 14.76 & & & & & & & \\
\hline ISSEI - ISSE2 & 36 & 17.75 & 15.86 & 0.468 & 0.004 & 23.38 & 23.11 & 6.71 & 35 & $0.007 *$ \\
\hline
\end{tabular}


clude direct follow-up questions to students' assessments of career services' interactions and compare them to the comments from career services.

\section{CONCLUSION}

This study found two scenarios in support for including interviewing instruction in the basic course curriculum. First, evidence suggests that students have few prior positive interactions with the campus career services department, and limited experience participating in mediated employment interviews. Lack of these interactions means less opportunities for students to practice their interviewing skills in "safe" (not judgmental or consequence-bearing) situations. Second, students anecdotally reported using employment interview strategies introduced during class to secure new internship and employment positions by the end of the course term. The above results further suggest that when students participate in instructional activities on interview strategies, their self-reported performance in the interview scenario is enhanced.

A unique comment noted value of the interview strategy instruction: "For many students this may be the only formal instruction they will have on this subject." With an average of two hours of additional instruction prior to their second-round simulated interviews, students felt that their abilities to effectively communicate job competency and necessary skills increased. Talking about how to overcome common interviewing mistakes in class was the greatest teaching tool for many students. As one student observed, "I have learned the way to dress for an interview, how to respond to interview questions, and where to conduct an interview (in relation to what interviewers can see behind the candidates during an online interview)." Students also commented that practicing using virtual software increased the likelihood of seeking additional counselling from career services and reviewing online training videos to better hone interviewing skills.

\section{REFERENCES}

Angiolillo, J. S., Blanchard, H. E., Israelski, E.W., \& Mané, A. (1997). Technology constraints of video-mediated communication. In K. Finn, A. Sellen, and S.Wilbur (Eds.), Video-mediated Communication (pp. 5I-73). Mahway, NJ: Lawrence Erlbaum.

Barnes, A. (20/4). Using video feedback to increase eye contact during mock job interviews for transition age adults with autism spectrum disorders. Graduate Theses and Dissertations. Retrieved from http://scholarcommons.usf.edu/etd/5 I 78

Blacksmith, N.; Willford, J. C.; \& Behrend, T. S. (20I6). Technology in the employment interview: A meta-analysis and future research agenda. Personnel Assessment and Decisions, 2(I),2.

Brenner, F. S., Ortner, T. M., \& Fay, D. (2016). Asynchronous video interviewing as a new technology in personnel selection: The applicant's point of view. Frontiers in Psychology, 7, 863. Retrieved from http://doi.org/l 0.3389/fpsyg.2016.00863

Britt, L. L., Brockman, S., Casson, W., \& Johnson, M. (2016). Construction of the "real world" in a communication studies curriculum: An opportunity for insight from the voices of faculty, student and alumni. Florida Communication Journal, 44(I).

Chapman, D. S., \& Rowe, P. M. (200I). The impact of videoconference technology, interview structure, and interviewer gender on interviewer evaluations in the employment interview: A field experiment. Journal of Occupational and Organizational Psychology, 74(3), 279-298.

Chapman, D. S., \& Rowe, P. M. (2002). The influence of videoconference technology and interview structure on the recruiting function of the employment interview: A field experiment. International Journal of Selection and Assessment, 10(3), I85-197.

Chapman, D.S., Uggerslev, K.L., Carroll, S.A., Piasentin, K.A., \& Jones, D. (2005). Applicant attraction to organizations and job choice: A meta-analytic review of the correlates of recruiting outcomes." Journal of Applied Psychology, 90:928-944.

Dey, F., \& Cruzvergara, C. (20I4). Evolution of career services in higher education. New Directions for Student Services, I48, 5-18.

Doria, J., Rozanski, H., \& Cohen, E. (2003). What business needs from business schools. Strategy \& Business, 32. Retrieved from http://www.strategy-business.com/press/article/03305?gko $=8 \mathrm{c} 56-1876-26073$

Dunbar, N. E., Jensen, M. L., Burgoon, J. K., Kelley, K. M., Harrison, K. J., Adame, B. J., \& Bernard, D. R. (20I5). Effects of veracity, modality, and sanctioning on credibility assessment during mediated and unmediated interviews. Communication Research, 42(5), 649-674.

Finch, D.J., Hamilton, L.K., Baldwin, R., \& Zehner, M. (20I3). An exploratory study of factors affecting undergraduate employability. Education \& Training, 55(7), 68I-704.

Finch, D.J., Nadeau, J. and O'Reilly, N. (20I2). The future of marketing education:A practitioners' perspective. Journal of Marketing Education, 35(I), 54-67.

Fischer, K. (20I3). The employment mismatch. Chronicle of Higher Education. Retrieved from: http://www.chronicle.com/article/The-Employment-Mismatch/I 37625.

Goodnight, L., \&Wallace, S. (Eds.). (2005). The basic communication course online: Scholarship and application. Dubuque, IA: Kendall/Hunt Publishing.

Guchait, P., Ruetzler, T., Taylor, J.,\& Toldi, N. (20I6). Video interviewing: A potential selection tool for hospitality managers - A study to understand applicant perspective. International Journal of Hospitality Management, 36, 90-100.

Hancock, A. B., Stone, M. D., Brundage, S. B., \& Zeigler, M.T. (20I0). Public speaking attitudes: Does curriculum make a difference? Journal of Voice, 24(3), 302-307.

Hansen, K., Oliphant, G.C., Oliphant, B.J., \& Hansen, R.S. (2009). "Best practices in preparing students for mock interviews. Business Communication Quarterly, 72(3), 318-327.

Helyer, R., \& Lee, D. (20I4). The role of work experience in the future employability of higher education graduates. Higher Education Quarterly, 68(3), 348-372.

Hooker, J. F., \& Simonds, C. J. (20I5). From the outside looking in: Employers' views of the basic course. Basic Communication Course Annual, 27(I), 12.

Johnson, J. R., \& Szczupakiewicz, N. (1987). The public speaking course: Is it preparing students with work related public speaking skills? Communication Education, 36(2), I 3 I- I 37.

Kinzel, R. H., Veltsos, J., Bates, R. A., Cohen, R. E., Sealy, W., \& Nykanen, D. K. (20I5, October). Evaluation and continuous improvement in a multidisciplinary S-STEM program focusing on professional skills, goals \& mentoring. In Frontiers in Education Conference (FIE), 2015 IEEE (pp. I-7). IEEE. 
Kurtz, S., Silverman, J., \& Draper, J. (2016). Teaching and learning communication skills in medicine. CRC Press.

Kyllonen, P. C. (2013). Soft skills for the workplace. Change: The Magazine of Higher Learning, 45(6), 16-23.

LeFebvre, L., LeFebvre, L. E., \& Allen, M. (20I6). The unaware, accurate, and overly critical:Video technology use of improving public speaking competency. Basic Communication Course Annual, 28(I3), I I6- I65.

Morreale, S. P., \& Backlund, P. M. (2002). Communication curricula: History, recommendations, resources. Communication Education, 5 I (I), 2-I8.

Morreale, S. P., Hanna, M. S., Berko, R. M., \& Gibson, J.W. (1999). The basic communication course at U.S. colleges and universities:VI. Basic Communication Course Annual, I I, I-36.

Morreale, S., Hugenberg, L., \& Worley, D. (2006). The basic communication course at U.S. colleges and universities in the 2 I st century: Study VII. Communication Education, 55(4), 4I 5 437.

Myers, L. L., \& Tucker, M. L. (2005). Increasing awareness of emotional intelligence in a business curriculum. Business Communication Quarterly, 68(I), 44-5I.

National Association of Colleges and Employers (NACE). (2016). Job outlook 2016: The attributes employers want to see on new college graduates' resumes. Retrieved from http:// www.naceweb.org/career-development/trends-and-predictions/job-outlook-20 I6-attributes-employers-want-to-seeon-new-college-graduates-resumes/

National Association of Colleges and Employers (NACE). (2017). Internship and co-op hiring make gains in 2017. Retrieved from: https://www.naceweb.org/job-market/internships/internship-and-co-op-hiring-make-gains-in-2017/

Ratcliff, A. J. (2017). The Influence of the medium: An examination of faculty and student experiences with online public speaking courses (Doctoral dissertation). Regent University, Virginia Beach,VA.

Robles, M. M. (20I2). Executive perceptions of the top $10 \mathrm{soft}$ skills needed in today's workplace. Business Communication Quarterly, 75(4), 453-465.
Rowell, A., \& Mihuta, T. (2016). Technology and career preparation: Using virtual interview recordings (VIRs) in an apparel, design, and textiles (ADT) professional seminar course. Journal of Family and Consumer Sciences, I08(2), 27.

Silvester, J., \& Anderson, N. (2003). Technology and Discourse: A Comparison of Face-to-face and Telephone Employment Interviews. International Journal of Selection and Assessment, II (2-3), 206-2I 4.

Smith, M. J., Boteler Humm, L., Fleming, M. F., Jordan, N.,Wright, M. A., Ginger, E. J., \& Bell, M. D. (20I5).Virtual reality job interview training for veterans with posttraumatic stress disorder. Journal of Vocational Rehabilitation, 42(3), 27I-279.

Smith, M. J., Ginger, E.J.,Wright, M.,Wright, K., Humm, L. B., Olsen, D., \& Fleming, M. F. (20|4). Virtual reality job interview training for individuals with psychiatric disabilities. The Journal of Nervous and Mental Disease, 202(9), 659.

Stewart, C.,Wall,A., \& Marciniec, S. (2016). Mixed signals: Do college graduates have the soft skills that employers want? In Competition Forum, I4(2), 276-28I.

Stocco, C. S., Thompson, R. H., Hart, J. M., \& Soriano, H. L. (20I7). Improving the interview skills of college students using behavioral skills training. Journal of Applied Behavior Analysis.

Straus, S. G., Miles, J.A., \& Levesque, L. L. (200I).The effects of videoconference, telephone, and face-to-face media on interviewer and applicant judgments in employment interviews. Journal of Management, 27(3), 363-38I.

Taylor, K. A. (2003). Marketing yourself in the competitive job market: An innovative course preparing undergraduates for marketing careers. Journal of Marketing Education, 25(2), 97. 107.

Toldi, N.L. (20I I). Job applicants favor video interviewing in the candidate-selection process. Employment Relations Today, 38(3), 19-27.

Valenzano III, J. M., Wallace, S. P., \& Morreale, S. P. (20I4). Consistency and change:The $(r)$ evolution of the basic communication course. Communication Education, 63(4), 355-365. 